\title{
MODELLING AND SIMULATION OF WATER GAS SHIFT REACTOR USING COMSOL MULTIPHYSICS
}

\author{
ADRIAN CATALIN SOIT ${ }^{\mathrm{a}}$, IONELA DUMBRAVA ${ }^{\mathrm{a}}$, \\ VLAD-CRISTIAN SANDUa , ANA-MARIA CORMOS ${ }^{a *}$
}

\begin{abstract}
Hydrogen production from fossil fuels plays an important role in the global $\mathrm{H}_{2}$ demand. In general, $\mathrm{H}_{2}$ production from fossil sources implies syngas generation, typically by gasification or reforming, followed by the water gas shift process. The aim of this work is to determine the behaviour of the water gas shift process (in a packed bed reactor) through modelling and simulation using COMSOL Multiphysics software. In the developed model, diffusion is the main type of transport of the chemical substances. The challenges are to model the complex phenomena associated with a multiscale system: a macroscale level in the macropores between the dumped catalyst particles and a microscale level, inside of the pellets' micropores.
\end{abstract}

Keywords: Hydrogen production, Water gas shift reactor, CFD modelling using COMSOL Multiphysics software.

\section{INTRODUCTION}

Fossil fuels supply the majority of the world's energy demand. Carbon dioxide obtained from fossil fuels contributes to climate change, therefore the main focus is now to produce clean and renewable energy. $\mathrm{H}_{2}$ is an important raw material for the chemical and petrochemical industries and could have an important part in alternative fuels [1]. To produce $\mathrm{H}_{2}$, there are a wide variety of processes, which according to the sources used, can be divided in two major categories: conventional and renewable technologies [2]. The conventional methods use fossil fuels as raw materials and include methods such as hydrocarbon reforming and hydrocarbon pyrolysis to produce $\mathrm{H}_{2}$. The reforming processes (steam reforming, partial oxidation and autothermal reforming) are the most developed at this moment to meet almost the entire

\footnotetext{
a Babeş-Bolyai University, Faculty of Chemistry and Chemical Engineering, 11 Arany Janos str., RO-400028, Cluj-Napoca, Romania

*Corresponding author e-mail: cani@chem.ubbcluj.ro
} 
hydrogen demand. The renewable methods use biomass and water in order to obtain hydrogen. In biomass processes there are two subtypes of methods: one implies thermochemical processes and the second one uses biological processes. The second renewable method, water splitting, uses only water as the source of $\mathrm{H}_{2}$ through electrolysis, thermolysis and photo-electroysis process [2]. In general, $\mathrm{H}_{2}$ production from fossil sources implies syngas generation, typically by gasification or reforming followed by water gas shift (WGS) process. Carbon dioxide and other impurities, obtained after WGS conversion, are separated in a hydrogen purification unit (Figure 1).

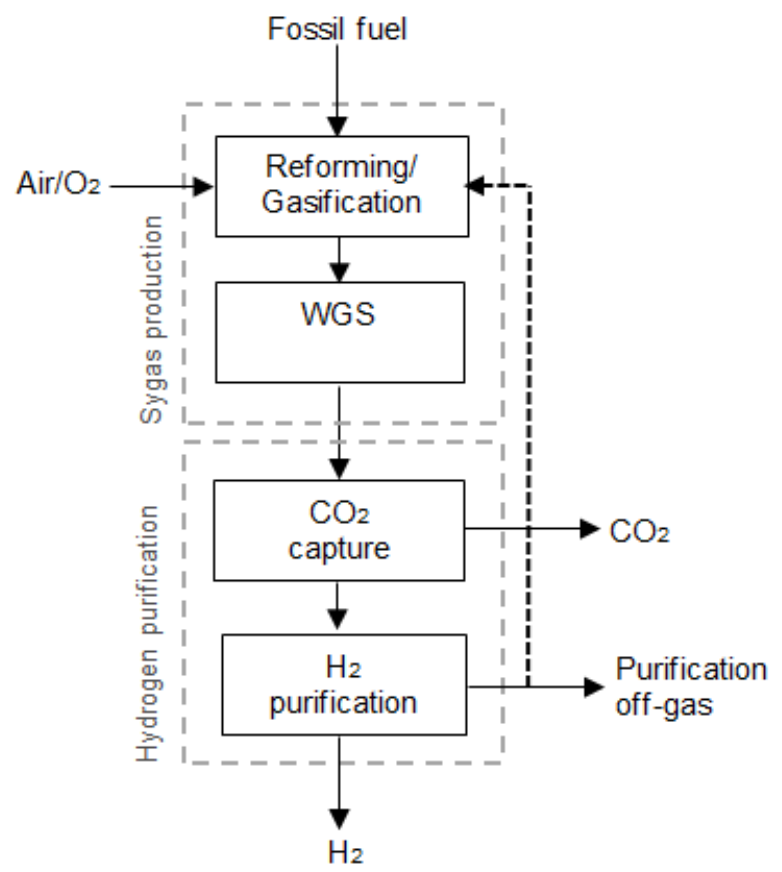

Figure 1. Steam reforming of natural gas [1]

Currently, steam reforming of natural gas produces $48 \%$ of the total hydrogen demand. Consequently, steam reforming with emphasis on water gas shift deserves special attention. Natural gas can be converted to syngas, followed by the WGS reaction to produce carbon dioxide and hydrogen from water vapors and carbon monoxide [1]:

$$
\mathrm{CO}_{(\mathrm{g})}+\mathrm{H}_{2} \mathrm{O}_{(\mathrm{g})} \leftrightarrow \mathrm{CO}_{2(\mathrm{~g})}+\mathrm{H}_{2(\mathrm{~g})} \quad \Delta_{\mathrm{r}} \mathrm{H}_{298}^{0}=-9.84 \frac{\mathrm{kcal}}{\mathrm{mol}}
$$


In process industry, the water gas shift reaction takes place in 2 steps. In the first one, the carbon monoxide concentration decreases from $10-13 \%$ to $2-3 \%$ (molar \%). The temperature for the first step is between 350 $550{ }^{\circ} \mathrm{C}$, depending on the inlet gas composition. The pressure is between 20-30 bar and the gas velocity can reach from 400 to $1200 \mathrm{~m} \cdot \mathrm{h}^{-1}$, related to the dry quantity of the gas [2]. The high-temperature catalysts used for water gas shift conversion are presented in Table 1.

Table 1. High temperature catalysts [1]

\begin{tabular}{|l|l|}
\hline Catalyst properties & Working conditions \\
\hline $\mathrm{CuO} \cdot \mathrm{CeO} \cdot 8 \mathrm{O}_{2}-\mathrm{y}\left(\mathrm{Cu}-\mathrm{CeO}_{2}\right)$ & $473-623.15 \mathrm{~K}, \mathrm{CO} / \mathrm{H}_{2} \mathrm{O}=1 / 3$ \\
$\mathrm{Fe}_{3} \mathrm{O}_{4} / \mathrm{Cr}_{2} \mathrm{O}_{3}, 180-250 \mu \mathrm{m}$ & $1 \mathrm{bar}, 6$ bar, 27 bar, \\
& $623-713.15 \mathrm{~K}$ \\
$\mathrm{Fe}_{3} \mathrm{O}_{4} / \mathrm{Cr}_{2} \mathrm{O}_{3}$ & $3-5$ bar, $846-906.15 \mathrm{~K}$ \\
$89 \% \mathrm{Fe}_{2} \mathrm{O}_{3}, 9 \% \mathrm{Cr}_{2} \mathrm{O}_{3}$ & $575-675.15 \mathrm{~K}$ \\
$80-95 \% \mathrm{Fe}_{2} \mathrm{O}_{3}$, & $1 \mathrm{~atm}, 723.15 \mathrm{~K}$, \\
$5-13 \% \mathrm{Cr}_{2} \mathrm{O}_{3}, 1-5 \% \mathrm{CuO}$ & \\
$\mathrm{CuO} / \mathrm{Fe}_{3} \mathrm{O}_{4} / \mathrm{Cr}_{2} \mathrm{O}_{3}$, & 1 bar, 6 bar, 27 bar, \\
$180-250 \mu \mathrm{m}$ & $653-723.15 \mathrm{~K}$ \\
$0.4 \% \mathrm{Pt}^{\prime} / \mathrm{Al}_{2} \mathrm{O}_{3}$ & 1 atm, $817.15 \mathrm{~K}$ \\
$1 / 4 " \times 3 / 8 ", 2.20 \mathrm{~g} / \mathrm{cm}^{3}$ & Power Gas - pilot plant \\
$1 / 4 " \times 1 / 4 ", 1.25 \mathrm{~g} / \mathrm{cm}^{3}$ & Girdler - pilot plant \\
$11.3 " \times 8.5 \mathrm{~mm}, 1.35 \mathrm{~g} / \mathrm{cm}^{3}$ & ICl - pilot plant \\
\hline
\end{tabular}

The second step of the WGS process takes place at low temperature, lower than $250{ }^{\circ} \mathrm{C}$, and the carbon monoxide concentration is reduced to a $0.2-0.4 \%$ concentration. The low-temperature catalysts used for water gas shift conversion operate between 200 and $250^{\circ} \mathrm{C}$ [3] (Table 2).

Table 2. Low temperature catalysts $[1,3]$

\begin{tabular}{|l|l|}
\hline Catalyst properties & Working conditions \\
\hline $\mathrm{CuO}-\mathrm{ZnO}-\mathrm{Al}_{2} \mathrm{O}_{3}$, & $393-523.15 \mathrm{~K}$ \\
$200-250 \mu \mathrm{mm}$ & \\
$1-2 \% \mathrm{Pt} / \mathrm{Al}_{2} \mathrm{O}_{3}$ & $1 \mathrm{~atm}, 498-618.15 \mathrm{~K}$ \\
$8-10 \% \mathrm{Cu}-\mathrm{Al}_{2} \mathrm{O}_{3}$ & $1 \mathrm{~atm}, 403-473.15 \mathrm{~K}$ \\
$\mathrm{Cu}(111)$ & $1 \mathrm{~atm}, 613.15 \mathrm{~K}$ \\
\hline
\end{tabular}

The most common reactors for the heterogeneous catalytic processes (in the case of WGS process) in the chemical industry are the packed bed reactors. The packed bed reactor is a column filled with porous catalyst particles (pellets) and can be packed in one compartment or can contain 
supporting structures (channels or tubes). Depending on the way the gas is passing through the catalyst bed, there are 2 types of columns: with axial or radial flow of the gas.

\section{MODEL DEVELOPMENT}

Modelling and simulation of the water-gas shift process was made using COMSOL Multiphysics 5.2. A packed bed reactor filled with spherical catalyst pellets was chosen for this study (Figure 2). The packed bed reactor makes modelling of mass transfer and chemical reactions a challenge, rising from the fact that the transfer of species and the chemical reaction take place at different orders of magnitude, one at macroscale level in the macropores between the dumped catalyst particles and the second one at microscale level, inside of the micropores of the pellets [4]. The multiscale problem was solved with COMSOL Multiphysics software, using "Reactive Pellet Bed" feature, available in "Transport of Diluted Species" interface, specifically designed for this kind of problem [5].

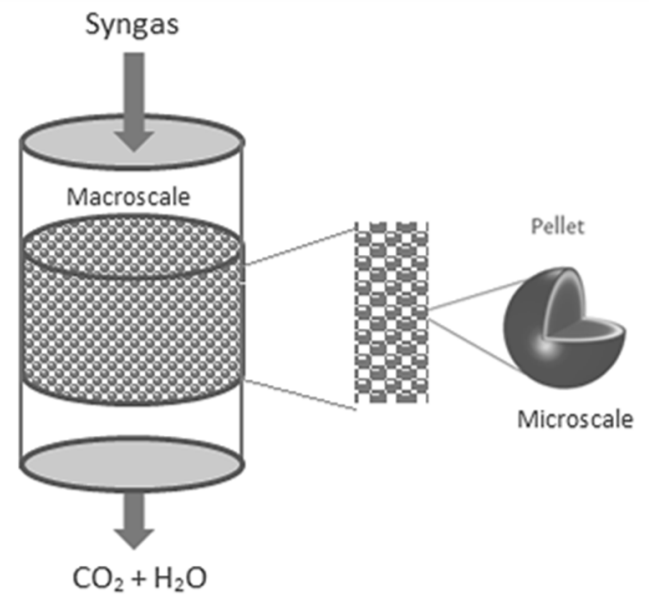

Figure 2. A macro and microscale of a packed bed reactor

The heterogeneous model is developed to account for the diffusional limitations. Certain assumptions have to be made for the overall reactor model:

- Mass transport inside the catalyst pellets, along the reactor length, takes place by diffusional and convective mechanisms;

- Catalyst pellets have a homogenous and porous structure;

- Mass transfer within the catalyst pellets occurs only in the radial direction;

- Reaction rate depends on the mass transfer inside the catalyst pellets. 
Model equations at macroscale level [5]

The pressure drop along the reactor length is described by Ergun's equation:

$$
-\frac{d P}{d x}=\frac{150 \mu u}{D_{p}{ }^{2}} \cdot \frac{\left(1-\varepsilon_{b}\right)^{2}}{\varepsilon_{b}{ }^{3}}+\frac{1.75 \rho u^{2}}{D_{p}} \cdot \frac{\left(1-\varepsilon_{b}\right)}{\varepsilon_{b}{ }^{3}}
$$

The mass transfer, which occurs by diffusional and convective mechanisms (for Transport of Diluted Species feature), is described by the following equation:

$$
\nabla\left(-D_{i} \nabla c_{i}+c_{i} u\right)=R_{i}
$$

The reaction rate source $R$ depends on the transport inside the catalyst pellets.

$$
R=\left(1-\varepsilon_{b}\right) A_{p}(N \cdot n), \text { at } r=r_{p}
$$

Model equations at microscale level [5]

The reaction rate within the catalyst pellet is affected by the mass transfer inside the pellet (only diffusional mechanism is considered). The mass balance at microscale level is described by the following equation, using the normalized radius of the catalyst particle:

$$
\nabla \cdot\left(-\left(\frac{r}{r_{p}}\right)^{2} D_{c p} \nabla c_{p}\right)+\left(\frac{r}{r_{p}}\right)^{2} \cdot R_{p}=0, \text { for } 0<r<1
$$

The distribution of the concentration in the pellet is represented by the following equation and describes the molar flux of the species according to the position in the reactor:

$$
R=\left(1-\varepsilon_{b}\right) A_{p}\left(-D_{c p} \nabla c_{p} \cdot n\right)
$$

Reaction kinetics

The kinetic model developed by Germani et al., 2005 is used to describe the water-gas shift reaction. The WGS reaction can be considered at equilibrium and the rate of reaction is represented by Equation 7 (RwGs unit is $\left[\mathrm{mol} \cdot \mathrm{m}^{-3} \cdot \mathrm{s}^{-1}\right]$ ) for the temperature range $573-673 \mathrm{~K}$ and depends on the catalyst density, partial pressure of the components, equilibrium constant and Arrhenius equation [6].

$$
R_{W G S}=\rho_{c a t} k_{W G S} e^{\left(-\frac{E_{W G S}}{R T}\right)} p_{C O}{ }^{0.13} p_{\mathrm{H}_{2} O^{0.49}} p_{C O_{2}}{ }^{-0.12} p_{\mathrm{H}_{2}}{ }^{-0.45}\left(1-\frac{p_{C_{2}} p_{\mathrm{H}_{2}}}{p_{C O} p_{\mathrm{H}_{2} \mathrm{O}} K_{W G S}}\right)
$$

The value of the pre-exponential factor is $k_{W G S}=1.3 \cdot 10^{6} \mathrm{~mol} /\left(\mathrm{kg}\right.$ cat $\left.\cdot \mathrm{s} \cdot \mathrm{Pa} a^{0.05}\right)$ and the activation energy is $E_{W G S}=86000 \mathrm{~J} / \mathrm{mol}$. 
The equilibrium constant is obtained using the following equation [7]:

$$
k_{W G S}=\exp (Z(Z(-0.1821 Z+0.563176)+4.189249)+0.341737)
$$

where $Z=1000 / T-1$.

\section{RESULTS AND DISCUSSION}

A summary of the packed bed reactor characteristics and operating data, used in this work, is presented in Table 3 . The developed model was validated with data from an industrial plant, published in literature [8].

Table 3. Reactor parameters, case 1 [9]

\begin{tabular}{|l|c|}
\hline Feed gas composition & $\%$ \\
\hline $\mathrm{CO}$ & 6.41 \\
$\mathrm{H}_{2} \mathrm{O}$ & 38.53 \\
$\mathrm{H}_{2}$ & 47.97 \\
$\mathrm{CO}_{2}$ & 4.54 \\
$\mathrm{Ar}$ & 2.55 \\
\hline Reactor & \\
\hline Height $(\mathrm{m})$ & 5.15 \\
Diameter $(\mathrm{m})$ & 2.15 \\
Catalyst pellets bed height $(\mathrm{m})$ & 3.65 \\
Catalyst pellets diameter $(\mathrm{m})$ & $4.4 \cdot 10^{-3}$ \\
Catalyst pellets density $\left(\mathrm{kg} / \mathrm{m}^{3}\right)$ & 1260 \\
Catalyst pellets porosity $(-)$ & 0.6 \\
Steam/CO ratio & 6 \\
Feed Flowrate $(\mathrm{kmol} / \mathrm{s})$ & 764.5 \\
Gas velocity $(\mathrm{m} / \mathrm{s})$ & 0.75 \\
Pressure $($ atm $)$ & 23.53 \\
Feed temperature $\left({ }^{\circ} \mathrm{C}\right)$ & 357 \\
\hline
\end{tabular}

To verify the accuracy of the results for the developed model, the distribution of the carbon monoxide conversion along the reactor length (case 1) was determined (Figure 3).

In the developed model, the WGS equilibrium reaction is approximated by using an expression for fast WGS kinetics, derived for a platinum/ceria/ alumina catalyst by Germani et al. [6]. The kinetics model was adapted to process conditions in order to achieve the output process parameters presented in literature [8]. The correlation coefficient, $R=0.9556$, indicates that there is a good correlation between the results of the simulation model in COMSOL and data presented in literature for water gas-shift process. 
MODELLING AND SIMULATION OF WATER GAS SHIFT REACTOR USING COMSOL ...

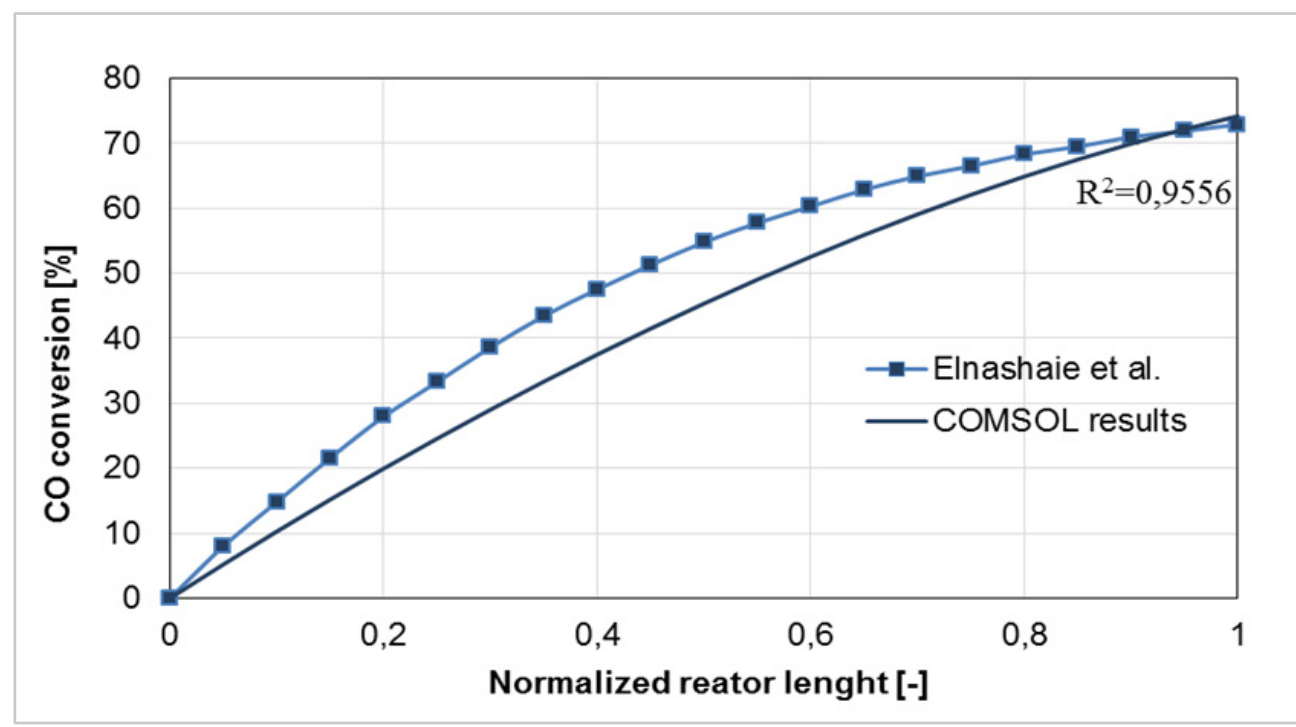

Figure 3. CO conversion along the normalized reactor length, case 1

In order to validate the developed mathematical model, a new simulation was done, using the adjusted model and different operating parameters presented in Table 4 . The simulation results show a good correlation with data presented in literature ( $R=0.9654)$ (Figure 4).

Table 4. Reactor parameters, case 2 [8]

\begin{tabular}{|l|c|}
\hline Feed gas composition & $\%$ \\
\hline $\mathrm{CO}$ & 5.22 \\
$\mathrm{H}_{2} \mathrm{O}$ & 43.90 \\
$\mathrm{H}_{2}$ & 47.40 \\
$\mathrm{CO}_{2}$ & 2.47 \\
$\mathrm{Ar}$ & 1.01 \\
\hline Reactor & \\
\hline Steam/CO ratio & 8.4 \\
Feed Flowrate $(\mathrm{kmol} / \mathrm{s})$ & 776 \\
Gas velocity $(\mathrm{m} / \mathrm{s})$ & 0.75 \\
Pressure $($ atm $)$ & 23.53 \\
Feed temperature $\left({ }^{\circ} \mathrm{C}\right)$ & 355 \\
\hline
\end{tabular}




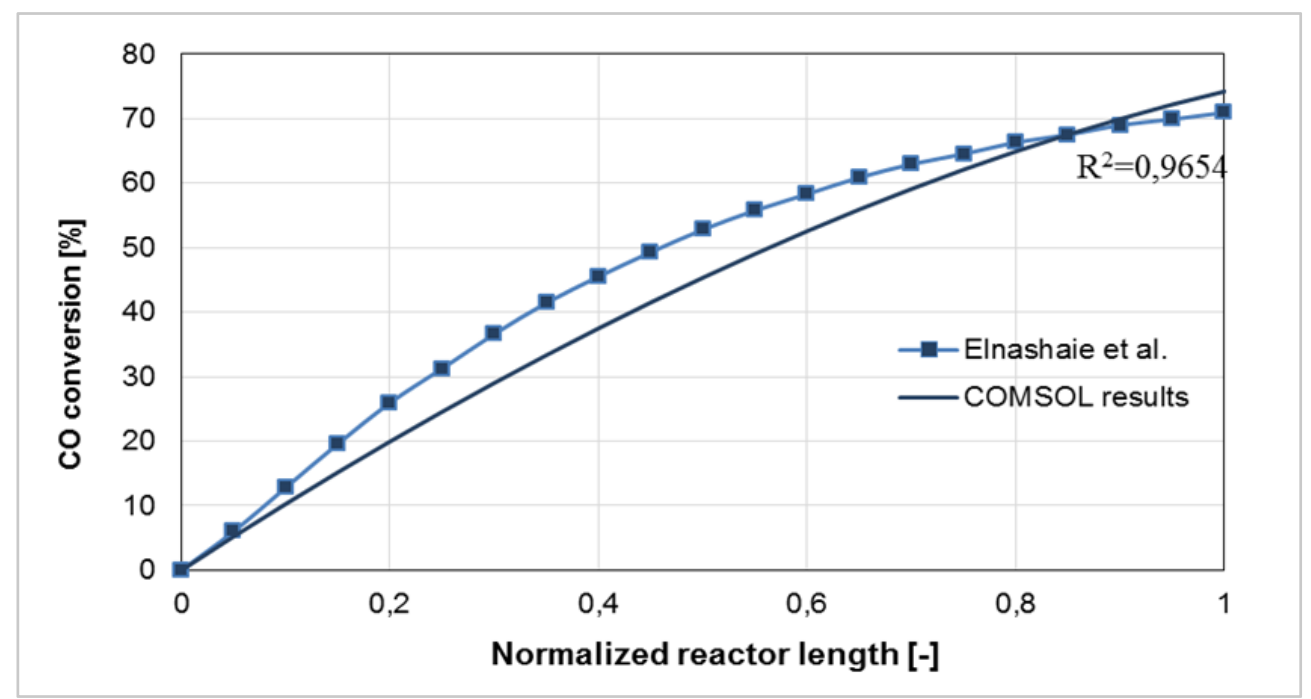

Figure 4. $\mathrm{CO}$ conversion along the normalized reactor length, case 2

Based on simulation of the developed model, the variation of the gaseous composition along the reactor length was determined (Figure 5), showing that carbon monoxide is almost fully converted and as result the hydrogen molar fraction is increasing along the reactor length.

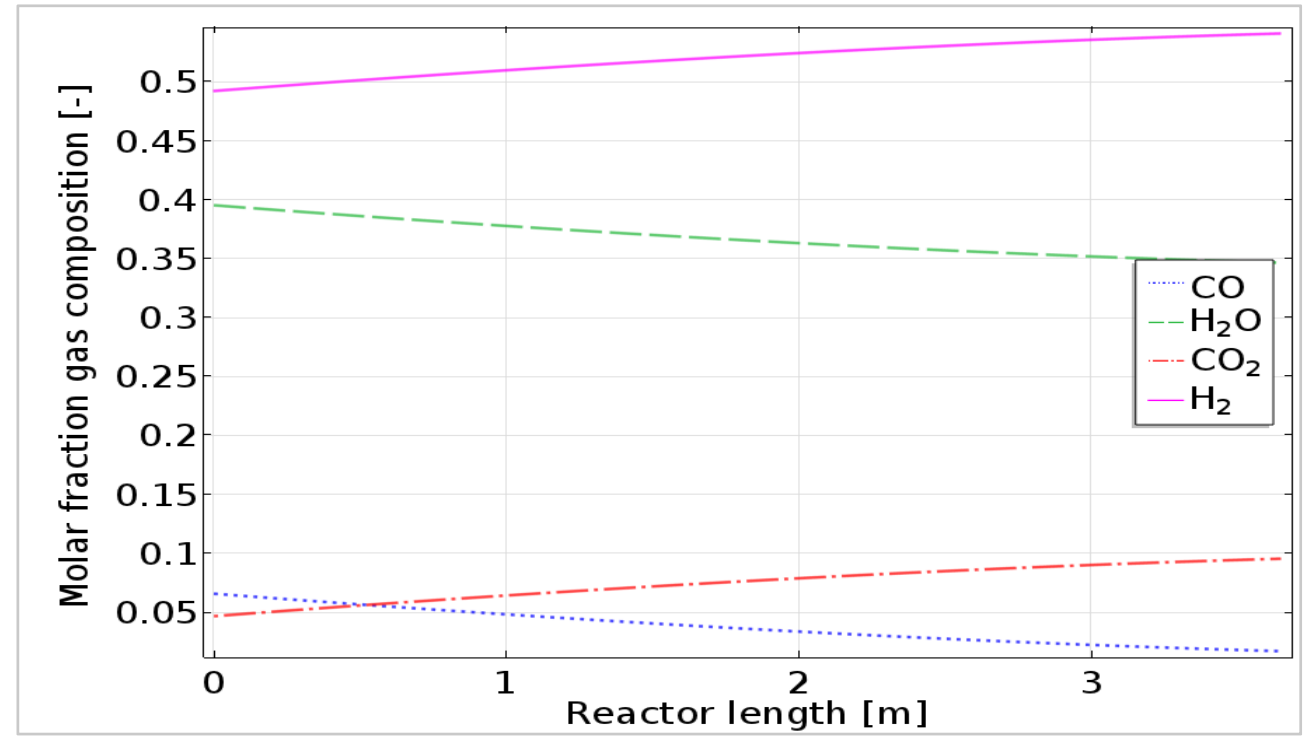

Figure 5. Gas composition distribution along the reactor length 
In order to see the distribution inside the reactor bed a 3D model was built. Based on computational time constrains only a small section of the reactor was chosen for simulation. Figure 7 shows the variation of $\mathrm{CO}$ partial pressure in the reactor, how has expected the concentration decrease from the inlet to the exit of the reactor.

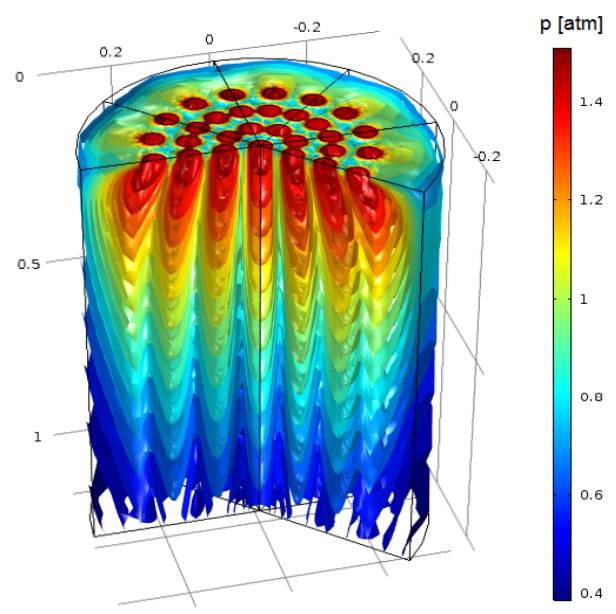

Figure 6. 3D partial pressure distribution of $\mathrm{CO}$ in the reactor

The highest partial pressure of hydrogen is at the catalyst pellet surface, where the chemical reaction occurs (Figure 7).

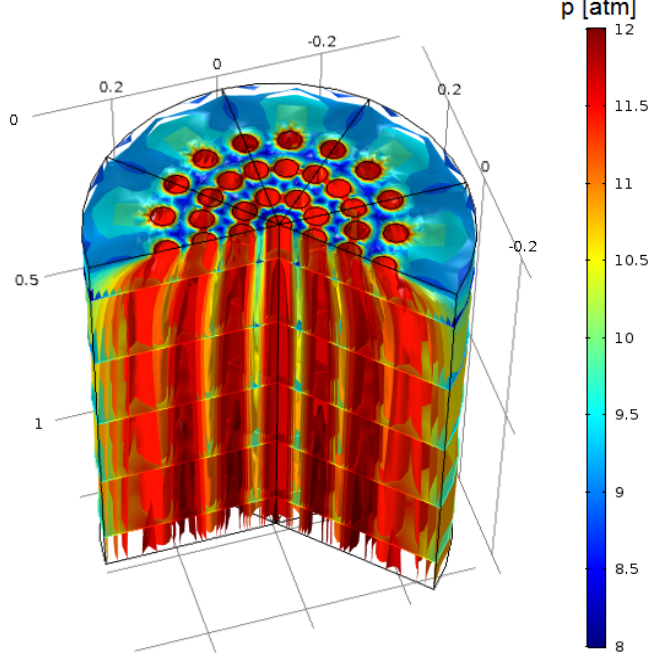

Figure 7. 3D partial pressure distribution of $\mathrm{H}_{2}$ in the reactor 


\section{CONCLUSIONS}

Hydrogen production from fossil fuels plays an important role in the global demand of $\mathrm{H}_{2}$, as a result, there is a significant interest in optimization and control of the process. A detailed mathematical model was developed for analysing hydrogen production through Water Gas Shift process in a packed bed reactor. The developed model of WGS is implemented and solved in COMSOL Multiphysics 5.2. Based on simulation of the developed model, the variation of the gaseous composition along the reactor length was determined. The developed model of water gas-shift process was validated with data collected from a pilot plant published in literature. The simulation results show a carbon monoxide conversion in range of $74.2 \%$ in line with the published data $(72.9 \%)$. Based on computational time constrains, a reactor bed section was simulated to see the gas composition on longitudinal and radial section, using 3D models.

The developed model described the WGS process only in the case of using high-temperature stage of catalyst. As future work in order to find the optimal working conditions of WGS reaction and to achieve a higher conversion of carbon monoxide (implicitly a higher amount of hydrogen) a low-temperature stage catalyst model would have to be implemented in COMSOL Multiphysics. The developed mathematical model would be used for analysing the water gas-shift process efficiency and understanding the micro level interactions of various processes taking place inside a packed bed reactor. Furthermore, the model would be used in evaluation of various operating conditions for optimization of technical indicators of the water gas-shift process.

\section{ACKNOWLEDGMENTS}

This work was supported by a grant of the Romanian National Authority for Scientific Research and Innovation, CCCDI - UEFISCDI, project number COFUND-ACT ERANET-3D-CAPS (contract number: 87/2017): "3D Printed Capture Materials for Productivity Step-Change", within PNCDI III. 


\section{NOMENCLATURE}

$\begin{array}{ll}A_{p} & \text { specific aria for granule, } \mathrm{m}^{2} / \mathrm{m}^{3} \\ c_{i} & \text { bulk concentration of specie } i, \mathrm{~mol} \mathrm{~m} \mathrm{~m}^{-3} \\ c_{p} & \text { bulk concentration of specie } i \text { catalyst granules, } \mathrm{mol} \mathrm{m}^{-3} \\ D_{i} & \text { molecular diffusion coefficient of specie } i, \mathrm{~m}^{2} \mathrm{~s}^{-1} \\ D_{c p} & \text { molecular diffusion coefficient inside of granule, } \mathrm{m}^{2} / \mathrm{s} \\ D_{p} & \text { particle diameter, } \mathrm{m} \\ n & \text { surface normalized vectors for granules } \\ N & \text { gas molar flow to catalyst surface }\left[\mathrm{mol} /\left(\mathrm{m}^{2} \cdot \mathrm{s}\right)\right] \\ p & \text { pressure, } \mathrm{Pa} \\ R_{i} & \text { reaction rate source, } \mathrm{mol} /\left(\mathrm{m}^{3} \cdot \mathrm{s}\right) \\ R_{p} & \text { reaction rate in micropore, } \mathrm{mol}^{\prime} /\left(\mathrm{m}^{3} \cdot \mathrm{s}\right) \\ r & \text { variable } \\ r_{p} & \text { particle radius, } \mathrm{m} \\ u & \text { velocity, } \mathrm{m} \mathrm{s} \mathrm{s}^{-1} \\ \varepsilon_{b} & \text { bed porosity, }- \\ \mu & \text { gas viscosity }[\mathrm{Pa} \cdot \mathrm{s}] \\ \rho & \text { fluid density, } \mathrm{kg} \mathrm{m} \mathrm{m}^{-3}\end{array}$

\section{REFERENCES}

1. S. Saeidi, F. Fazlollahi, S. Najari, D. Iranshashi, J. Klemes, L. Baxter, J. Ind. Eng. Chem., 2017, 49, 1-25.

2. P. Nikolaidis, A. Poullikkas, Renewable Sustainable Energ. Rev., 2017, 67, 597611.

3. C. Rhodes, G. Hutchings, A. Ward, Catalysis Today, 1995, 23, 43-58.

4. J. Rawlings, J. Ekerdt, "Chemical Reactor Analysis and Design Fundamentals", Nob Hill Publishing, Madison, 2002.

5. ${ }^{* * *}$, COMSOL Multiphysics User's Guide, version 5.2, COMSOL, Inc, www.comsol.com.

6. G. Germani, P. Alphonse, M. Courty, Y. Schuurman, C. Mirodatos, Catalysis Today, 2005, 110, 114-120.

7. H. Reijers, J. Boon, G. Elzinga, P. Cobden, W. Haije, R. van den Brink, Industrial \& Engineering Chemistry Research, 2009, 48, 6975-6982.

8. S. Elnashaie, F. Alhabdan, Mathematical Computer Modelling, 1989, 12, $1017-$ 1034. 
